This article was published in Water Research, 94, 10-22, 2016

http://dx.doi.org/10.1016/j.watres.2016.02.003

\title{
Photocatalytic ozonation of urban wastewater and surface water using immobilized TiO2 with LEDs: Micropollutants, antibiotic resistance genes and estrogenic activity
}

Nuno F.F. Moreira a, b, Jose M. Sousa b, Gonçalo Macedo ${ }^{c}$, Ana R. Ribeiro ${ }^{a}$, Luisa Barreiros d, Marta Pedrosa a , Joaquim L. Faria a, M. Fernando R. Pereira a, Sergio Castro-Silva e, Marcela A. Segundo d, Celia M. Manaia c, Olga C. Nunes b, , Adrián M.T. Silva a

a Laboratory of Separation and Reaction Engineering - Laboratory of Catalysis and Materials (LSRE-LCM), Faculdade de Engenharia, Universidade do Porto,

Rua Dr. Roberto Frias, 4200-465, Porto, Portugal

b LEPABE - Laboratory for Process Engineering, Environment, Biotechnology and Energy, Faculdade de Engenharia, Universidade do Porto, Rua Dr. Roberto Frias, 4200-465, Porto, Portugal

c CBQF-Centro de Biotecnologia e Química FinaeLaboratório Associado, Escola Superior de Biotecnologia, Universidade Cató lica Portuguesa/Porto, Rua

Arquiteto Lobã o Vital, Apartado 2511, 4202-401, Porto, Portugal

d UCIBIO, REQUIMTE, Departamento de Ciências Químicas, Faculdade de Farmá cia, Universidade do Porto, Rua de Jorge Viterbo Ferreira 228, 4050-313,

Porto, Portugal

e Adventech-Advanced Environmental Technologies, Centro Empresarial $e$



\begin{abstract}
Photocatalytic ozonation was employed for the first time in continuous mode with TiO2-coated glass Raschig rings and light emitting diodes (LEDs) to treat urban wastewater as well as surface water collected from the supply area of a drinking water treatment plant (DWTP). Different levels of contamination and types of contaminants were considered in this work, including chemical priority substances (PSs) and contaminants of emerging concern (CECs), as well as potential human opportunistic antibiotic resistant bacteria and their genes (ARB\&ARG). Photocatalytic ozonation was more effective than single ozonation (or even than $\mathrm{TiO} 2$ catalytic ozonation) in the degradation of typical reaction byproducts (such as oxalic acid), and more effective than photocatalysis to remove the parent micro- pollutants determined in urban wastewater. In fact, only
\end{abstract}


fluoxetine, clarithromycin, erythromycin and 17-alpha-ethinylestradiol (EE2) were detected after photocatalytic ozonation, by using solid-phase extraction (SPE) pre-concentration and LC-MS/MS analysis. In surface water, this treatment allowed the removal of all determined micropollutants to levels below the limit of detection (0.01-0.20 ng $\mathrm{L}^{-1}$ ). The efficiency of this process was then assessed based on the capacity to remove different groups of cultivable microorganisms and housekeeping (16S rRNA) and antibiotic resistance or related genes (intI1, blaTEM, qnrS, sul1). Photocatalytic ozonation was observed to efficiently remove microorganisms and ARGs. Although after storage total heterotrophic and ARB (to ciprofloxacin, gentamicin, meropenem), fungi, and the genes 16S rRNA and intI1, increased to values close to the pre-treatment levels, the ARGs (blaTEM, qnrS and sul1) were reduced to levels below/close to the quantification limit even after 3-days storage of treated surface water or wastewater. Yeast estrogen screen (YES), thiazolyl blue tetrazolium reduction (MTT) and lactate dehydrogenase (LDH) assays were also performed before and after photo- catalytic ozonation to evaluate the potential estrogenic activity, the cellular metabolic activity and the cell viability. Compounds with estrogenic effects and significant differences concerning cell viability were not observed in any case. A slight cytotoxicity was only detected for Caco-2 and hCMEC/D3 cell lines after treatment of the urban wastewater, but not for L929 fibroblasts.

\section{Introduction}

The environmental occurrence of priority substances (PSs), contaminants of emerging concern (CECs), human pathogens and antibiotic resistance genes (ARGs) is a serious issue affecting ecosystem services (such as drinking water supplies) and urban wastewater treatment plants (WWTPs) are hot spots for such type of contamination (Berendonk et al., 2015; Ribeiro et al., 2015a). For instance, conventional WWTPs are not specifically designed to eliminate PSs and CECs occurring at trace concentrations, ending into the environment. Among these, specific pesticides, endocrine disrupting compounds, industrial compounds, flame retardants, polycyclic aromatic hydrocarbons, dioxins and dioxin-like compounds, have already been identified as PSs in Directive 2013/39/EU (Directive, 2013). Furthermore, a watch list of 10 substances/groups of substances that should be monitored within the European Union was recently included in Decision 495/2015/EU (Decision, 2015), namely pharmaceuticals (diclofenac, 17-alphaethinylestradiol (EE2) and three macrolide antibiotics), two natural hormones (17- beta-estradiol (E2) and estrone (E1)), some pesticides, an UV filter and a food additive.

Besides the chemical contamination, the biological pollution is also a matter of concern in aquatic environments, in particular in human-impacted areas, calling for adequate responses from WWTPs (Dunlop et al., 2015; Ferro et al., 2015a; Michael et al., 2013; Rizzo et al., 2014). Conventional WWTPs, although able to remove the 
bacterial loads up to 2 logarithmic cycles, do not contribute to significant reductions of antibiotic resistance prevalence and, in some cases, can even contribute to its increase (Michael et al., 2013). It is estimated that urban conventional WWTPs using distinct types of biological treatments, and operating to achieve the recommended quality thresholds, release at least $10^{9}$ antibiotic resistant coliforms per minute to the surrounding environment (Vaz-Moreira et al., 2014).

Therefore, the spread of PSs, CECs and antibiotic resistant bacteria and their genes (ARB\&ARG) emitted from WWTPs contributes for the contamination of surface and groundwater, existing the possibility that some of these pollutants may reach the drinking water systems (Vaz-Moreira et al., 2014; Xi et al., 2009). This scenario makes also vulnerable the quality of treated wastewater and, thus, its reuse in activities such as irrigation in agriculture when this wastewater is not properly treated (Ferro et al., 2015b). In this context, new treatment options should be capable of eliminating PSs and CECs and reducing ARGs to levels at which further dissemination will be improbable (Berendonk et al., 2015; Dodd, 2012).

Chemical oxidation technologies (COTs) and advanced oxidation processes (AOPs), such as Fenton-based processes, heterogeneous photocatalysis and ozonation-based processes, have been widely studied to eliminate PSs and CECs from different types of waste- water, but most studies are focused on single compounds, normally at concentrations higher than those found in urban wastewater (Ribeiro et al., 2015a). In addition, photocatalysis (with or without $\mathrm{H}_{2} \mathrm{O}_{2}$ ) and the photo-Fenton process were already tested for the inactivation of an antibiotic resistant Escherichia coli strain (Dunlop et al., 2015; Ferro et al., 2015a; Rizzo et al., 2014). However, more studies are still needed to better understand the effect of the oxidative approaches on the control of ARB\&ARG. For instance, photocatalytic ozonation has been studied for the removal of pharmaceuticals in effluents from urban WWTPs (Beltran et al.,

2012; Encinas et al., 2013; Espejo et al., 2013; Li et al., 2007; Má rquez et al., 2014; Moreira et al., 2015; Quiñones et al., 2015; Rey et al., 2014; Tanaka et al., 2001), and a couple of reviews were published last year (Mehrjouei et al., 2015; Xiao et al., 2015), but not much is known about the potential of photocatalytic ozonation to remove ARB\&ARGs from urban wastewater. Much less information can be found regarding surface water. In fact the literature is still scarce, less than 300 publications being found in Scopus for "photocatalytic ozonation", against more than 35,500 for "photocatalysis" and 12,000 for "ozonation or ozonolysis", in January 2016. The high efficiency of the photocatalytic ozonation treatment has been explained by a synergistic effect between ozonation and photocatalysis. The photogenerated electrons can react with ozone molecules generating ozonide radicals while decreasing the possible recombination of electronehole pairs (Mehrjouei et al., 2015; Sá nchez et al., 1998).

Based on this background information, the present study aimed at performing a comprehensive evaluation of the capacity of photocatalytic ozonation to treat wastewater collected after the secondary treatment of an urban WWTP. These experiments were performed in continuous mode implementing an innovative 
approach with $\mathrm{TiO} 2$-coated glass Raschig rings (Sampaio et al., 2013) and light emitting diodes (LEDs). The same process was tested for surface water treatment, aiming at producing water fulfilling the requirements of drinking water. Thus, different levels of contamination and different types of contaminants were considered in this work, including a set of chemical PSs and CECs, some selected from Directive, 2013/39/EU (Directive, 2013) and Decision 495/2015/EU (Decision, 2015), as well as potential human opportunistic pathogens and ARGs. Yeast estrogen screen (YES), thiazolyl blue tetrazolium reduction (MTT) and lactate dehydrogenase (LDH) assays were also performed before and after photocatalytic ozonation to evaluate biological effects, including the potential estrogenic activity, the cellular metabolic activity and the cell viability in fresh and treated waters. Because biological contaminants have the potential to regrow, when the stress conditions imposed by the water treatment processes are relieved, microbiological indicators were also monitored after storage of treated water.

\section{Materials and methods}

\subsection{Chemicals and materials}

$\mathrm{TiO}_{2}$ (80\% anatase and 20\% rutile crystalline phases) was pro- vided by Evonik Degussa GmbH (P25). Ultrapure water (resistivity > $18 \mathrm{MU} \mathrm{cm}$ ) was supplied by a Milli-Q water system. Methanol and acetonitrile (MS grade) were acquired from VWR International (Fontenay-sous-Bois, France) whereas methanol and ethanol (HPLC grade) as well as orthophosphoric acid were purchased from Fisher Scientific UK Limited (Leicestershire, UK). Sulphuric acid was purchased from Merck (Darmstadt, Germany). Oxamic acid (>96\%) was supplied by Fluka (Buchs, Switzerland).

Anhydrous sodium dihydrogen phosphate, sodium chloride and oxalic acid (>99\%) were purchased from Sigma-Aldrich (Steinhein, Germany), as well as all reference standards for liquid chromatography (>98\% purity): diclofenac sodium, ibuprofen sodium, naproxen, tramadol hydrochloride, azithromycin dihydrate, clarithromycin, erythromycin, sulfamethoxazole, trimethoprim, fluticasone propionate, montelukast sodium, warfarin, clopidogrel hydrogen sulphate, metoprolol tartrate, propranolol hydrochloride, hydrochlorothiazide, atorvastatin calcium salt trihydrate, bezafibrate, simvastatin, carbamazepine, citalopram hydrobromide, fluoxetine hydrochloride, norfluoxetine oxalate, venlafaxine hydrochloride, diphenhydramine, 17-alpha-ethinylestradiol (EE2), 17-betaestradiol (E2), estrone (E1), alachlor, atrazine, simazine, diuron, isoproturon, chlorfenvinphos, pentachlorophenol, clofibric acid and perfluorooctanesulfonic acid. Stock solutions of each individual compound (approximately $1000 \mathrm{mg} \mathrm{L}^{-1}$ ) were prepared in methanol, ethanol or acetonitrile, depending on their solubility, and a working solution (200 $\mathrm{mg} \mathrm{L}^{-1}$ ) was prepared by diluting these solutions in 
ethanol. The deuterated compounds used as internal standards were also purchased from Sigma-Aldrich (Steinhein, Germany), namely: ketoprofen-d3, ofloxacine-d3, propranolol-d7 solution, fluoxetine-d5 solution, E2-d5 solution and atrazine-d5. A working solution containing $10 \mathrm{mg} \mathrm{L}^{-1}$ of all internal standards was prepared by diluting individual stock solutions (1000 $\left.\mathrm{mg} \mathrm{L}^{-1}\right)$ in ethanol.

For cell culture experiments, dimethyl sulfoxide ( $\geq 99.9 \%)$, Dulbecco's phosphate buffered saline (PBS) pH 7.4, Triton ${ }^{\mathrm{TM}} \mathrm{X}-100$, thiazolyl blue tetrazolium (MTT) an trypan blue powder were purchased from Sigma-Aldrich. Dulbecco's modified eagle media (DMEM; ref: 31966-021), heat inactivated fetal bovine serum (FBS), penicillin-streptomycin (PenStrep) and trypsin-EDTA were purchased from Gibcoß by Life Technologies ${ }^{\mathrm{TM}}$ (UK). EndoGRO ${ }^{\mathrm{TM}}$ e MV complete media kit was obtained from Merck Millipore and LDH Cytotoxicity Detection Kit was acquired from Takara Bio Inc. (Shiga, Japan). Caco-2 cell line was purchased to the American Type Culture Collection (ATCC, Wesel, Germany) and used between passage number 35 and 42. hCMEC/D3 cell line was kindly supplied by the Institut National de la Santé et de la Recherche Mé dicale (INSERM, Paris, France) and used between the passage number 31 to 34. Murine fibroblasts L929 were also obtained from ATCC.

\subsection{Experimental set-up and procedure}

A bubble column reactor (Fig. 1a; 2.2 I.D.x $60 \mathrm{~cm}$ height) equipped with a loop column (Fig. 1b; 2.2 I.D.x $15 \mathrm{~cm}$ height) was used for all the experiments.

This reactor was designed for ozonation experiments operating in continuous mode (Restivo et al., 2012a) and equipped with LEDs in the present work. Two $10 \mathrm{~W}$ UV high intensity LEDs $(15.5 \mathrm{~mm} \times 23 \mathrm{~mm})$, with dominant emission line at $382 \mathrm{~nm}$ and long service life (intensity remains above $70 \%$ after 10,000 h work) (Fig. $1 \mathrm{k}$ and $\mathrm{m}$ ), were placed perpendicularly to each other, irradiating the stream (distance of $5 \mathrm{~cm}$ ) passing through the loop column, by setting a recirculation flow rate of $60 \mathrm{~mL} \mathrm{~min}-1$ (Fig. $1 \mathrm{~g}$ ), as performed in a previous work dealing with catalytic ozonation (Restivo et al., 2012b). The wavelength around $382 \mathrm{~nm}$ was chosen considering a compromise between the cost of LEDs (increasing when the emission wavelength decreases) and the possibility to achieve an overlapping between the LEDs main emission wave- length and the $\mathrm{TiO} 2$ absorption spectrum. LEDs emitting in UV-C wavelengths can be up to 10 times more expensive than those emitting in near visible wavelengths. In addition, operation at lower wavelengths demands more energy, the LEDs lifetime de- creases significantly (Lui et al., 2014), and energy is wasted in the form of heat. For these reasons, the wavelength near $382 \mathrm{~nm}$ was seen as the best option to the system under study, in this way using the minimum energy to activate the TiO2 photocatalyst.

The loop column was packed with seventy three TiO2-coated glass Raschig rings (Fig. 1b) that were prepared as described else- where (Sampaio et al., 2013), from a procedure adapted from literature (Quici et al., 2010). Uncoated Raschig 
rings were used in non-catalytic assays. In photolysis and photocatalytic experiments, the LEDs were switched on at the beginning of the experiment, with a constant oxygen flow rate $\left(15 \mathrm{Ncm}^{3} \mathrm{~min}^{-1}\right)$. In ozonation and photocatalytic ozonation assays, a BMT 802X ozone generator (Fig. 1c) was used to produce ozone (from pure oxygen) at a constant inlet concentration (50 $\left.\mathrm{g} \mathrm{Nm}^{-3}\right)$ and flow rate $\left(15 \mathrm{Ncm}^{3} \mathrm{~min}^{-1}\right)$. A BMT 964 ozone analyzer (Fig. 1f) was used to control the concentration of ozone in the gas phase. Gas washing bottles filled with potassium iodide solution were used to remove the ozone leaving the reactor in the gas phase (Fig. 1e).

Regardless of the type of test performed, the reactor was always filled with ultrapure water and the experiment started ( $t \quad 0 \mathrm{~min})$ when the water to be treated (wastewater or surface water) (Fig. 1i) was pumped to the reactor (Fig. 1h), i.e., being diluted until achieving the steady state. Thus, since the reactor was fully filled with ultrapure water before starting the experiment with a realistic matrix, some dilution occurred up to $90 \mathrm{~min}$ in every run. This reactor is designed to operate in continuous mode, with a continuous entrance of realistic matrix at the bottom of the biggest column (liquid flow rate of $15 \mathrm{~mL} \mathrm{~min}^{-1}$ ), a continuous outlet stream of treated surface water/wastewater at the top of the same column, and a continuous recirculation $\left(60 \mathrm{~mL} \mathrm{~min}^{-1}\right)^{1 / 4}$ between the biggest column and the smaller column holding the photocatalyst, in this way simulating a perfectly mixed reactor. Thus, the removal efficiency was inferred when the steady state was achieved, i.e. when the outlet solution had always the same concentration and there was no more dilution effect. For this reason, preliminary studies on hydraulic retention time (HRT) were performed using $\mathrm{NaCl}$ as tracer (inlet concentration of $2000 \mathrm{mg} \mathrm{L}^{-1}$ ) and uncoated Raschig glass rings were placed randomly inside the loop column, measuring the conductivity with a conductimeter Crison GLP 31 (Barcelona, Spain). The gas and liquid streams were maintained at $15 \mathrm{Ncm}^{3} \mathrm{~min}^{-1}$ and $15 \mathrm{~mL} \mathrm{~min}-1$, having into account preliminary ozonation experiments with different ozone flow rates (using oxalic acid as prove molecule) and that these conditions were optimized for catalytic ozonation in a previous work (Restivo et al., 2012b). The HRT studies allowed to determine the time needed to achieve the steady state and the time spent by the fluid inside the reactor (retention time). Fig. 2 shows the evolution of the normalized conductivity $(\mathrm{s} / \mathrm{st})$ where $\mathrm{s}$ is the conductivity of the outlet solution and $\mathrm{st}$ the conductivity of the tracer injected in the column. The time needed to achieve the steady state is ca. $90 \mathrm{e} 100 \mathrm{~min}$ and the retention time (26 min) was determined from the area under the representation of $1-(\mathrm{s} / \mathrm{st})$ vs. time. Other run was performed with vertically aligned uncoated glass rings but the results were similar to those obtained with randomly distributed glass rings. Having into account these results, the next experiments were performed during 180 min with randomly distributed Raschig glass rings (retention time $=26 \mathrm{~min}$ ).

The first set of experiments with chemical pollutants was performed with 
ultrapure water spiked with diclofenac ( $32 \mathrm{mg} \mathrm{L}^{-1}$; $\mathrm{pH}$ 4.5) and the removal of this pharmaceutical was followed over time by analysing the treated effluent (Fig. 1j). In a second set of experiments, wastewater samples collected after the activated sludge biological treatment of an urban WWTP located in Northern Portugal were treated by ozonation, photocatalysis and photo- catalytic ozonation $(n=3$, i.e. a total of three samples for each treatment, each sample collected in a different day). For the catalytic treatments, coated Raschig glass rings were replaced between experiments. The sampling (April-May 2015) was performed using pre-rinsed amber glass bottles (2.5 L). Surface water samples were collected (May-June 2015) in the supply area of a drinking water treatment plant (DWTP) and treated by photocatalytic ozonation $(n=3)$. All samples were transported at $4{ }^{\circ} \mathrm{C}$ to the laboratory and processed immediately.

\subsection{Materials characterization}

TiO2-coated glass rings were characterized before and after the photocatalytic ozonation treatment. Scanning electron microscopy (SEM) and energy-dispersive X-ray spectroscopy (EDS) were per- formed in a FEI Quanta 400 FEG ESEM/EDAX Genesis X4M instrument. The materials hydrophilicity was assessed by measuring the water contact angle in an Attension equipment (Theta model) which allows image acquisition and data analysis. The measurements were performed at room temperature using the sessile drop method in five different locations over glass rings. Thermogravimetric (TG) analysis was performed using a STA $490 \mathrm{PC} / 4 / \mathrm{H}$ Luxx Netzsch thermal analyzer by heating the samples from room temperature until $800{ }^{\circ} \mathrm{C}$ at $10{ }^{\circ} \mathrm{C} \mathrm{min}^{-1}$ under helium flow, holding this temperature for $7 \mathrm{~min}$ and finally changing to air atmosphere during $13 \mathrm{~min}$.

\subsection{Chemical analysis}

High performance liquid chromatography with diode array detection (HPLCDAD) was performed to analyze the removal of diclofenac, using a Hitachi Elite Lachrom apparatus equipped with a YMC Hydrosphere C18 column (250 mm x 4.6 $\mathrm{mm}$ i.d.), working at room temperature under isocratic elution. The mobile phase consisted in a mixture of phosphate buffer solution ( $\mathrm{pH} 2.8$ ) and methanol $(30 / 70, \mathrm{v} / \mathrm{v})$. The flow rate was $1 \mathrm{~mL} \mathrm{~min}^{-1}$ and the volume of injection was 15 mL. A pH meter pHenomenal ${ }^{\circledR} \mathrm{pH} 1100 \mathrm{~L}$ (VWR, Germany) was used for all pH adjustments. The oxalic and oxamic acid concentrations were determined by HPLC-UV, using an Altech AO-1000 column (300 mm x $6.5 \mathrm{~mm}$ i.d.) operating under isocratic elution with $5 \mathrm{mM} \mathrm{H} 2 \mathrm{SO}_{4}$ at $0.5 \mathrm{~mL} \mathrm{~min}^{-1}$. The total organic carbon (TOC) content was determined using a Shimadzu TOC-5000A analyzer. The concentrations of the target micro- pollutants (listed in section 2.1) were determined in urban waste- water and surface water samples, before and after the 
treatment by the advanced oxidation processes, using a fully validated method of solid phase extraction (SPE) and ultra-high performance liquid chromatography with tandem mass spectrometry (UHPLC-MS/MS) in a Shimadzu Corporation apparatus (Tokyo, Japan), as described elsewhere (Ribeiro et al., 2015b). Wastewater $(100 \mathrm{~mL})$ and surface water $(250 \mathrm{~mL})$ samples were acidified to $\mathrm{pH} 3$ with sulphuric acid, followed by extraction of the micropollutants using Oasis ${ }^{\circledR}$ HLB (Hydrophilic-Lipophilic-Balanced sorbent, $150 \mathrm{mg}, 6 \mathrm{~mL}$ ) cartridges (Waters, Milford, Massachusetts, USA). For internal calibration, isotopically labeled internal standards were added to the samples before SPE.

\subsection{Microbiological characterization, DNA extraction and $q P C R$ analysis}

Wastewater and surface water samples were characterized for the abundance of different groups of cultivable microorganisms, quantification of selected antibiotic resistance and related genes (herein referred to ARG), before and immediately after photo- catalytic ozonation, and after three days of water storage at room temperature. For each photocatalytic ozonation experiment, all assays were performed in triplicate. The membrane filtration method was used for the enumeration of cultivable microorganisms. Briefly, adequate serial dilutions of water samples were filtered through cellulose membrane filters $(0.22 \mathrm{~mm}$ porosity; Whatman, UK) and incubated on culture media targeting different microbial groups: Plate Count Agar (PCA) (Merck, $30^{\circ} \mathrm{C}, 1 \mathrm{e} 7$ days) for total heterotrophs; membrane Fecal Coliforms (Difco, $37^{\circ} \mathrm{C}, 1$ day) for enterobacteria; $\mathrm{m}$-Enterococcus agar (Difco, $37^{\circ} \mathrm{C}, 2$ days) for enterococci; and Rose Bengal Chloramphenicol agar (VWR International, $30{ }^{\circ} \mathrm{C}, 7$ days) for fungi. Additionally, PCA supplemented with

ciprofloxacin $\left(4 \mathrm{mg} \mathrm{L}^{-1}\right)$, gentamicin $\left(16 \mathrm{mg} \mathrm{L}^{-1}\right)$ or meropenem $\left(4 \mathrm{mg} \mathrm{L}^{-1}\right)$ were used to assess resistance prevalence in surface water before and after treatment. These antibiotics were selected because resistance to carbapenems (e.g., meropenem) and aminoglycosides (e.g., gentamicin) is commonly found in drinking water bacteria or because selection of fluoroquinolone resistance (e.g., ciprofloxacin) is sometimes observed in aquatic environments (Vaz-Moreira et al., 2014). For culture-independent assays, total DNA was extracted from water samples with volumes ranging from $100 \mathrm{~mL}$ to $1 \mathrm{~L}$, after filtration through polycarbonate membranes $(0.22 \mu \mathrm{m}$ porosity; Whatman, UK), using the commercial kit PowerWater® DNA Isolation (MO BIO Laboratories, Inc., USA). DNA extracts were cryopreserved at $20{ }^{\circ} \mathrm{C}$ until the analyses of the abundance of ARG. Quantitative PCR (qPCR) was used according to the conditions indicated in Table 1, as described elsewhere (Narciso-da-Rocha et al., 2014).

2.6. Biological assays

2.61. Yeast estrogen screen (YES) assay

The YES assay was performed using the commercially available kit XenoScreen 
YES/YAS assay (Xenometrix, Hé genheim, France).

Water samples (wastewater and surface water) collected before and after photocatalytic ozonation were filtered through $0.45 \mathrm{~mm}$ hydrophilic membranes and directly analyzed, without any pre- concentration. The assay and potential estrogenic activity calculations were carried out following the manufacturer's instructions. Briefly, samples were transferred to a $96^{-}$well microplate, mixed with assay medium and inoculated with the transformed yeast cells. Assay mixture consisted of growth medium containing the chromogenic substrate chlorophenol red-b-D-galactopyranoside (CPRG). The natural estrogen E2, at concentrations between $10^{-6}-10^{-9} \mathrm{M}$, was used as positive control and standard. Ultrapure water was used as negative control. A solvent blank was also assayed. The plate was incubated for $48 \mathrm{~h}$ at $31^{\circ} \mathrm{C}$ with orbital shaking. After incubation, spectrophotometric measurements were performed in a microplate reader (Synergy HT, Bio-Tek Instruments, Winooski, USA) at $690 \mathrm{~nm}$ for growth and at $570 \mathrm{~nm}$ for expression of b-galactosidase. The potential estrogenic activity was determined through the calculation of the parameters growth factor $(G)$ and induction ratio (IR). The $\mathrm{G}$ parameter was calculated as the ratio of absorbance at $690 \mathrm{~nm}$ for the sample (A690) sample and the absorbance at $690 \mathrm{~nm}$ for the solvent (A690) solvent. The IR parameter was calculated as $(1 / \mathrm{G}) \mathrm{x}$ ((A570-A690) $\left.)_{\text {sample/(A570-A690 }}\right)_{\text {solvent }) .}$

26. Thiazolyl blue tetrazolium reduction (MTT) and lactate dehydrogenase (LDH) assays

Thiazolyl blue tetrazolium reduction (MTT) assay evaluates cellular metabolic activity while lactate dehydrogenase (LDH) assay provides information about cell viability through evaluation of membrane integrity. Cell culture procedures are described in detail elsewhere (Ferreira et al., 2015). Briefly, samples were diluted 1:2.5 in culture medium. Afterwards, $100 \mathrm{~mL}$ of diluted sample were added to cell layers or suspension, containing $100 \mathrm{~mL}$ of culture medium. After $24 \mathrm{~h}$, the supernatant was removed for LDH assay, while the remaining content was used for MTT assay. For MTT assay, absence of cytotoxicity (100\%) was evaluated by replacing test sample by culture medium. For LDH assay, absence of cell viability $(100 \%)$ was evaluated by replacing test sample by $1 \%(\mathrm{v} / \mathrm{v})$ Triton $\mathrm{X}^{-} 100$ solution in PBS.

\section{Results and discussion}

\subsection{Degradation oforganic micropollutants}

The first set of experiments with chemical pollutants was performed using ultrapure water spiked with diclofenac as model compound, due to the known high occurrence of this pharmaceutical in the environment, its recalcitrance, and inclusion in the watch list for European Union monitoring in the field of water 
policy (Decision, 2015). The evolution of the normalized concentration of diclofenac is shown in Fig. 3a, the time needed to achieve the steady state in all the experiments being around $90 \mathrm{e} 100 \mathrm{~min}$, as concluded from HRT studies (Fig. 2). Fig. 3a shows that complete removal of this compound was achieved in all the experiments where ozone was employed (ozonation, photolysis assisted ozonation, catalytic ozonation, and photocatalytic ozonation). For (non-catalytic) photolysis, the outlet and inlet diclofenac concentrations were practically the same in steady state. This result was expected since this model compound absorbs maximally radiation at wavelengths below $325 \mathrm{~nm}$ while the radiation peak of the used LEDs was centered at $382 \mathrm{~nm}$, above 367 and below $410 \mathrm{~nm}$ (Fig. 1m). In the case of $\mathrm{TiO}_{2}$-coated glass rings photocatalysis, a modest diclofenac removal in steady state was observed (ca. $26 \%$; i.e. $C / C 0=0.74$ ).

Oxalic and oxamic acids are well known reaction products during ozonation of larger molecules (Faria et al., 2008), and thus they were also analyzed, but only oxalic acid was detected above the limit of detection e LOD (Fig. 3b). As expected, oxalic acid was not formed during photolysis, while photocatalysis originated a low amount of this acid in steady state (ca. $2.0 \mathrm{mg} \mathrm{L}^{-1}$ ), which is probably related to the poor efficiency of this process for the degradation of diclofenac. In contrast, ozonation alone led to the largest amount of oxalic acid (ca. $13.0 \mathrm{mg} \mathrm{L}^{-1}$ ), followed by photolysis assisted ozonation and catalytic ozonation (ca. $10.5 \mathrm{mg} \mathrm{L}^{-1}$ ), and then by photocatalytic ozonation (ca. $9.0 \mathrm{mg} \mathrm{L}^{-1}$ ). TOC analysis was performed to account for the presence of other organic compounds that can be formed during the degradation of diclofenac (Fig. 3c). Once again, photolysis and photocatalysis were the least effective treatments, with TOC removals of ca. 3 and $20 \%$ in steady state, respectively, while photolysis assisted ozonation and photocatalytic ozonation were the best performing options in terms of TOC removal (ca. $51 \%$ and $56 \%$, respectively).

Since oxalic acid was the main by-product detected from diclofenac degradation, additional experiments were performed having oxalic acid only (90 $\mathrm{mg} \mathrm{L}^{-1}$ ) in ultrapure water as feed (Fig. 3d). Oxalic acid was completely recalcitrant in the photolysis assay, while low removal values were obtained with ozonation (8\%) and catalytic ozonation (11\%). All the other processes (photocatalysis, photolysis assisted ozonation and photocatalytic ozonation) were quite effective in the removal of oxalic acid ( $55 \%, 58 \%$ and $66 \%$, respectively). Even so, photocatalytic ozonation was more efficient than photolysis assisted ozonation for the degradation of oxalic acid, probably due to the overlap between the absorption spectrum of TiO2 and the emission spectrum of the LEDs, enough to get the minimum energy needed to surpass the energy band gap of $\mathrm{TiO}_{2}$. In batch conditions (Moreira et al., 2015), it was already observed that oxalic acid (one of the main reaction by-products in ozonation-based processes) is oxidized efficiently by photocatalytic ozonation, while photolysis assisted ozonation was not able to remove the oxalic acid accumulated. In addition, it is known that UV at $382 \mathrm{~nm}$ (far from UV-C) is inefficient for disinfection in the absence of a photocatalyst (Nelson et 
al., 2013). Thus, considering the targeted simultaneous treatment of both chemical and bio- logical contaminants, and since a photocatalyst can increase the process disinfection efficiency by the formation of highly reactive radicals, photocatalytic ozonation was applied to treat wastewater samples collected after the secondary biological treatment of an urban WWTP. Ozonation and photocatalysis experiments were also performed in order to assess the individual contribution of each process on their own.

The micropollutants (pharmaceuticals, a metabolite, hormones, pesticides and an industrial compound listed in section 2.1) were analyzed (before and after the treatment) by UHPLC-MS/MS, after pre-concentration of the samples by SPE. Fig. 4 shows the con- centration range for the detected micropollutants in the effluent of the biological treatment used in the urban WWTP during the sampling campaign (April-May 2015). The highest concentrations were observed for the following compounds with a frequency of detection of $100 \%$ (9/9): the antiinflammatory naproxen, the diuretic hydrochlorothiazide, the lipid regulator bezafibrate and the synthetic hormone EE2 included in the watch list of the Decision 495/2015/EU (Decision, 2015). Diclofenac, azithromycin, clarithromycin and erythromycin, also included in the watch list, as well as ibuprofen, clopidogrel, propranolol, atorvastatin, carbamazepine, fluoxetine and norfluoxetine, were quantified in all samples. Citalopram and venlafaxine were also detected, but not always above the limit of quantification (LOQ), whereas sulfa- methoxazole, trimethoprim, diphenhydramine, E2 and isoproturon were not detected in some samples.

Fig. 5 shows that the higher efficiency to remove the detected micropollutants was found for ozonation and photocatalytic ozonation. Photocatalysis was comparatively less effective in the degradation of these micropollutants. Only fluoxetine, clarithromycin, erythromycin and EE2 were detected in the outlet solution after photocatalytic ozonation. While both antibiotics were only detected in the final effluent of one of the triplicate experiments, fluoxetine and EE2 were detected twice. Naproxen was only quantified in one replicate assay. It is also important to note that samples were collected daily for each experiment. Regarding the TOC removal, the initial TOC of ca. $25 \mathrm{mg} \mathrm{L}^{-1}$ decreased to $19 \mathrm{mg} \mathrm{L}^{-1}$ in steady state conditions of photocatalytic ozonation. The initial and final $\mathrm{pH}$ values were quite similar (7.4 and 7.2 , respectively) while the low weight carboxylic acids and ions were below the LOQs. Thus, both single ozonation and photocatalytic ozonation treatments were quite effective to remove the chemical organic micropollutants (Fig. 5), but it should be also taken into account that ozonation is typically much less effective than photocatalytic ozonation in the mineralization (Fig. 3c) and degradation of typical reaction by-products (Fig. 3b). Among different treatments described elsewhere in batch conditions (Moreira et al., 2015), photocatalytic ozonation was considered the best performing process: a fast mineralization of amoxicillin and diclofenac was observed in spiked urban wastewater; toxic intermediate products for Escherichia coli and Staphylococcus aureus were not detected; and the parent micropollutants 
determined were removed from an urban wastewater.

Photocatalytic ozonation, the most efficient process for the degradation and mineralization of chemical pollutants in urban wastewater, was also tested to treat surface water samples collected near a DWTP. The micropollutants detected after pre-concentration of the samples by SPE were: clarithromycin, fluoxetine, nor- fluoxetine, carbamazepine, EE2, E2 and isoproturon (Table 2). The antibiotic clarithromycin, recently included in the watch list of substances for monitoring (Decision, 2015), was quantified at trace concentrations (up to $4.13 \mathrm{ng} \mathrm{L} \mathrm{L}^{-1}$ ). Fluoxetine was also detected in all samples, but only quantified in one sample (at $5.72 \mathrm{ng} \mathrm{L}^{-1}$ ), while its human metabolite norfluoxetine was detected once in the same sample, with a higher concentration $\left(7.66 \mathrm{ng} \mathrm{L^{-1 } )}\right.$ than the parent compound. The highest levels were obtained for the anti-epileptic carbamazepine (up to $56.2 \mathrm{ng} \mathrm{L}^{-1}$ ) and for the pesticide isoproturon (up to 24.3 ng $\mathrm{L}^{-1}$ ), the last considered as PS (Directive, 2013). All these micropollutants were completely removed by photocatalytic ozonation. Although not quantifiable, EE2 and E2 were detected before photocatalytic ozonation and completely removed. Therefore, photocatalytic ozonation was observed as an efficient treatment for the degradation of organic micropollutants in both urban wastewater and surface water.

\subsection{TiO2-coated glass rings characterization}

The TiO2-coated glass rings (shown in Fig. 6a) were character- ized by different techniques before and after photocatalytic ozon- ation of the urban wastewater samples. A negligible weight loss (WL) was obtained by TG analysis of the fresh TiO2-coated glass rings (not shown), regardless of the atmosphere employed (helium or air). In the case of the rings recovered after photocatalytic ozonation, desorption of water occurred below $100{ }^{\circ} \mathrm{C}$ under helium atmosphere while $4 \%$ of the weight decreased when the gas phase was shifted from helium to air at 800 ${ }^{\circ} \mathrm{C}$, most probably due to the oxidation of some organic matter remaining in the surface of these rings after photocatalytic ozonation. SEM micrographs, EDS spectra and contact angles of water droplets over the glass rings are shown in Fig. $6 \mathrm{~b}$ and c, respectively before and after the photo- catalytic ozonation treatment. TiO2 presence is evident in both samples, with Fig. 6 d showing a higher SEM magnification of the $\mathrm{TiO} 2$ particles. It is also possible to conclude that TiO2-coated glass rings are highly hydrophilic since very low contact angles were obtained $\left(<15^{\circ}\right)$. Overall, no significant differences were observed between the fresh and used samples, even considering the high matrix complexity of effluents from urban WWTPs.

\subsection{Microbial inactivation and reactivation}

The photocatalytic ozonation of secondarily treated wastewater showed the 
reduction of enterococci, enterobacteria, and fungi from $\sim 10^{5}$ e $10^{6}$ colony forming units (CFU) per $100 \mathrm{~mL}$ to values around or below $\sim 10^{1} \mathrm{CFU} / 100 \mathrm{~mL}$. In contrast, total heterotrophs that may comprise bacteria with different levels of endurance, such as endospore producers, presented lower reductions, with about $\sim 10^{2}$ CFU/100 $\mathrm{mL}$ being detected after the advanced treatment (Fig. 7a). These results were confirmed in the assays testing the regrowth capacity, with significantly higher counts of total heterotrophic populations and fungi than of the other microbial groups analyzed. Regrowth may have resulted from the combination of treatment survival and capacity to use any available carbon and energy sources. Indeed, the occurrence of microbial regrowth after water treatment has been attributed to the presence of assimilable organic carbon, generated during the oxidation of recalcitrant organic matter (Thayanukul et al., 2013; Zhao et al., 2014). The comparison of the regrowth capacity in the presence of light or in the dark, suggested that light may have facilitated the recovery of cell injuries, mainly in bacterial heterotrophs and fungi (Fig. 7a), as previously described (Hijnen et al., 2006).

Since most of the microorganisms in water are not cultivable, and advanced water treatment may enhance the fraction of non- cultivable populations, the use of culture-independent methods was necessary in this study. In spite of their stress status, some bacteria maintain viability, being able to regrow when the disinfection stress is relieved. From some of these bacterial cells, DNA extraction may be not possible immediately after surface water/ wastewater treatment, therefore the measurement of the same target genes after three days of incubation was a way to assess the abundance of bacteria fitted to survive after disinfection. Of the analyzed genes, 16S rRNA, intI1, blaTEM, qnrS and sul1 were above the LOQ in the secondarily treated wastewater samples analyzed. The gene vanA was below the LOD (Fig. 7c). Photocatalytic ozonation led to a significant reduction of total prokaryotic cells (assessed based on the abundance of the 16S rRNA gene) and of the gene intI1, associated with mobile gene cassettes, also with widespread distribution in different bacterial groups. In addition, also the antibiotic resistance genes blaTEM, qnrS and sul1 were significantly reduced after the photocatalytic ozonation. These genes, although highly prevalent in human impacted environments were originally at lower abundance than 16S rRNA and intI1 genes, and were reduced to levels below or close the LOQ ( 10 gene copies per $\mathrm{mL}$ ) after photocatalytic ozonation. For the genes $16 \mathrm{~S}$ rRNA and intI1, the reduction observed after treatment was apparently a transient effect. After storage in the dark or presence of light, the gene copy numbers per $100 \mathrm{~mL}$ of 16S rRNA and intI1 genes were about 1 logarithmic cycle below the initial value (Fig. 7c). The other analyzed genes did not yield a significant increase in their relative abundance during storage (Fig. 7c). These results were also useful to measure the effectiveness of the treatment process, with the regrowth capacity representing a good indication of the fraction of live cells remaining immediately after treatment. 
Regarding surface water, the photocatalytic ozonation treatment produced similar results to those obtained for the secondarily treated wastewater. Except for total heterotrophs, the photocatalytic ozonation treatment led to the removal of the analyzed microbial groups (Fig. 7b) to values close to or below the LOD $\left(10^{-2} \mathrm{CFU} / 100 \mathrm{~mL}\right)$. However, regrowth was observed for fungi and was particularly enhanced for total heterotrophs. In addition, in this case, the analysis of specific potential antibiotic resistant populations suggested that bacteria with acquired anti- biotic resistance traits may have the capacity to regrow in photocatalytic ozonated water up to values found in non-treated surface water (Fig. 8). Similar conclusions were retrieved in a study where the effect of chlorination and $\mathrm{H}_{2} \mathrm{O}_{2}$ /sunlight processes on the regrowth of a multidrug Escherichia coli strain was investigated (Fiorentino et al., 2015).

In surface water the genes qnrS, vanA and sul1 were below the LOQ, while blaTEM presented $10^{4}$ gene copy number per $100 \mathrm{~mL}$ (Fig. 7d). Photocatalytic ozonation treatment led to reductions of around 3 logarithmic cycles of the $16 \mathrm{~S}$ rRNA and intI1 genes, and the gene blaTEM was reduced to levels close to the LOQ. As for wastewater, for 16S rRNA and intI1 genes, the inactivation effect was apparently transient (Fig. $7 \mathrm{~d}$ ), corroborating the cultivable- dependent data. Although these findings may suggest a potential increase of microbiological risks, it would be necessary to study the diversity of the populations and/or the prevalence of resistance genes among them to have a better estimation of potential risks.

\subsection{Biological effects}

YES assay results revealed that no agonistic estrogenic activity was found for samples collected before and after photocatalytic ozonation treatment of the WWTP effluent, along with no growth inhibition. The IR values determined for both samples were be- tween 0.804 and 1.074, which is below IR10 (1.487 for E2). These observations indicate that the proposed treatment strategy did not originate compounds with estrogenic effects. Furthermore, cytotoxicity and cellular viability assays using cell models for digestive epithelium (Caco-2), bloodbrain barrier (hCMEC/D3), and skin (L929) showed no significant difference concerning cell viability (Table $3, \mathrm{LDH}$ assay). MTT assay is a suitable tool for assessment of cytotoxic effects from wastewater, surface water and drinking water samples as reported before (Trintinaglia et al., 2015; egura et al., 2009). Slight cytotoxicity was observed for Caco-2 and hCMEC/D3 cell lines after treatment, but not for L929 fibroblasts (Table 3, MTT assay). The first two cell lines are human-derived, while L929 fibroblasts were originated in mouse, accounting for their different susceptibility. Furthermore, as reported before (Trintinaglia et al., 2015), the exposure to water testing sample mixed with culture media can originate different results, depending upon the final growth media composition.

Regarding the surface water, no agonistic estrogenic activity was found for these 
samples when using the YES assay, along with no growth inhibition. The IR values determined for both samples were between 0.681 and 0.962 , which is also below IR10 (1.487 for E2). These observations corroborate that the proposed treatment strategy did not originate compounds with estrogenic effects. Similar results were obtained when applying recombinant yeasts expressing estrogen receptor alpha to evaluate the estrogenic activity of wastewater, bottled waters and tap water in Finnish samples (Omoruyi and Pohjanvirta, 2015). For LDH assay, cellular viability was maintained after treatment for both Caco-2 and hCMEC/D3 cells, providing values similar to those obtained for culture media.

\section{Conclusions}

Among different oxidative treatments tested in continuous mode, photocatalytic ozonation using $\mathrm{TiO}_{2}$-coated glass Raschig rings with LEDs irradiation was the most efficient for the removal of PSs and CECs from urban wastewater. In these experiments, fluoxetine, clarithromycin, erythromycin and EE2 were more refractory to oxidation than the other compounds. The same process completely removed all the micropollutants detected in surface water (carbamazepine, isoproturon, clarithromycin, norfluoxetine, fluoxetine, E2 and EE2). In addition, the efficiency to remove different groups of cultivable microorganisms and housekeeping (16S rRNA) and antibiotic resistance or related genes (intI1, blaTEM, qnrS, sul1) was studied, with photocatalytic ozonation showing high efficiency on the removal of microbial loads, including ARG, from both urban wastewater and surface water. The tested ARGs were successfully removed to levels below/close to the threshold of quantification. Moreover, after the 3-days storage of treated surface water/wastewater at room temperature, there was no evidence of regrowth of the host, as inferred from the absence of an increase in the relative abundance of the respective ARG. However, both culturedependent and -independent methods demonstrated that part of the surface water/wastewater microbiota was viable, able to regrow, and the potential risk of this regrowth is still to be assessed. From YES, MTT and LDH assays it follows that compounds with estrogenic effects were not formed and that differences concerning cell viability were not statistically significant for both urban wastewater and surface water. Therefore, photocatalytic ozonation proved to be a potential solution for simultaneous removal of organic micropollutants, different microbial groups of potential human pathogens, ARB and ARG present in wastewater or surface water. However, more studies are still required as well as the evaluation of the process associated costs. 


\section{Acknowledgments}

Financial support for this work was provided by project NORTE- 07-0202FEDER-038900 (NEPCAT), financed by FEDER (Fundo Europeu de Desenvolvimento Regional) through ON2 (Programa Operacional do Norte). This work was partially co-financed by FCT (Fundação para a Ciência e a Tecnologia)/MEC and FEDER under Programme PT2020 (Projects UID/EQU/50020/2013 - POCI-01- 0145-FEDER-006984, UID/Multi/50016/2013 and UID/Multi/04378/2013), and by QREN, ON2, FCT and FEDER through projects NORTE- 07-0124-FEDER-000015 and NORTE-07-0162-FEDER-000050. NFFM, ARR, LB and MP acknowledge financial support from FCT grants PD/BD/114318/2016, SFRH/BPD/101703/2014, SFRH/BPD/89668/2012 and SFRH/BD/102086/2014, respectively. AMTS ac- knowledges the FCT Investigator 2013 Programme (IF/01501/2013), with financing from the European Social Fund and the Human Potential Operational Programme. Technical assistance of CEMUP team with SEM analysis is gratefully acknowledged. The authors would like to acknowledge the financial support provided by COST- European Cooperation in Science and Technology, to the COST Action ES1403: New and emerging challenges and opportunities in wastewater reuse (NEREUS). Disclaimer: The content of this article is the authors' responsibility and neither COST nor any person acting on its behalf is responsible for the use, which might be made of the information contained init.

\section{References}

Beltrả n, F.J., Aguinaco, A., García-Araya, J.F., 2012. Application of ozone involving advanced oxidation processes to remove some pharmaceutical compounds from urban wastewaters. Ozone Sci. Eng. 34 (1), 3-15.

Berendonk, T.U., Manaia, C.M., Merlin, C., Fatta-Kassinos, D., Cytryn, E., Walsh, F., Burgmann, H., Sorum, H., Norstrom, M., Pons, M.-N., Kreuzinger, N., Huovinen, P., Stefani, S., Schwartz, T., Kisand, V., Baquero, F., Martinez, J.L., 2015. Tackling antibiotic resistance: the environmental framework. Nat. Rev. Micro. 13 (5), 310-317.

Bibbal, D., Dupouy, V., Ferré, J.P., Toutain, P.L., Fayet, O., Prẻ re, M.F., Bousquet-Mẻ lou, A., 2007. Impact of three ampicillin dosage regimens on selection of ampicillin resistance in Enterobacteriaceae and excretion of blaTEM genes in swine feces. Appl. Environ. Microbiol. 73 (15), 47854790.

Decision, 2015. Commission implementing Decision (EU) 2015/495 of 20 March 2015 establishing a watch list of substances for Union-wide monitoring in the field of water policy pursuant to directive 2008/105/EC of the European Parliament and of the Council. Off. J. Eur. Union L78, 40-42.

Denman, S.E., McSweeney, C.S., 2006. Development of a real-time PCR 
assay for monitoring anaerobic fungal and cellulolytic bacterial populations within the rumen. FEMS Microbiol. Ecol. 58 (3), 572-582.

Directive, 2013. Directive 2013/39/EU of the European Parliament and of the Council of 12 August 2013 amending directives 2000/60/EC and 2008/105/EC as regards priority substances in the field of water policy. Off. J. Eur. Union L226, 1-17.

Dodd, M.C., 2012. Potential impacts of disinfection processes on elimination and deactivation of antibiotic resistance genes during water and wastewater treatment. J. Environ. Monit. 14 (7), 1754-1771.

Dunlop, P.S.M., Ciavola, M., Rizzo, L., McDowell, D.A., Byrne, J.A., 2015. Effect of photocatalysis on the transfer of antibiotic resistance genes in urban wastewater. Catal. Today 240, Part A, 55-60.

Encinas, Ả., Rivas, F.J., Beltr'an, F.J., Oropesa, A., 2013. Combination of black-light photo-catalysis and ozonation for emerging contaminants degradation in secondary effluents. Chem. Eng. Technol. 36 (3), 492-499.

Espejo, A., Aguinaco, A., Amat, A.M., Beltrả n, F.J., 2013. Some ozone advanced oxidation processes to improve the biological removal of selected pharmaceutical contaminants from urban wastewater. J. Environ. Sci. Health A 49 (4), 410-421.

Faria, P.C.C., O’ rfã o, J.J.M., Pereira, M.F.R., 2008. Activated carbon catalytic ozonation of oxamic and oxalic acids. Appl. Catal. B 79 (3), 237-243.

Ferreira, M., Chaves, L.L., Lima, S.A.C., Reis, S., 2015. Optimization of nanostructured lipid carriers loaded with methotrexate: a tool for inflammatory and cancer therapy. Int. J. Pharm. 492 (1e2), 65-72.

Ferro, G., Fiorentino, A., Alferez, M.C., Polo-Ló pez, M.I., Rizzo, L., Fern'andez- Ibảñez, P., 2015a. Urban wastewater disinfection for agricultural reuse: effect of solar driven AOPs in the inactivation of a multidrug resistant E. coli strain. Appl. Catal. B 178, 65-73.

Ferro, G., Polo-Ló pez, M.I., Martínez-Piernas, A.B., Fernả ndez-Ibả ñ ez, P., Agüera, A., Rizzo, L., 2015b. Cross-contamination of residual emerging contaminants and antibiotic resistant bacteria in lettuce crops and soil irrigated with wastewater treated by Sunlight/H2O2. Environ. Sci. Technol. 49 (18), 11096-11104.

Fiorentino, A., Ferro, G., Alferez, M.C., Polo-Ló pez, M.I., Fern'andezIban ez, P., Rizzo, L., 2015. Inactivation and regrowth of multidrug resistant bacteria in urban wastewater after disinfection by solar-driven and chlorination processes. J. Photochem. Photobiol. B Biol. 148, 43-50.

Goldstein, C., Lee, M.D., Sanchez, S., Hudson, C., Phillips, B., Register, B., Grady, M., Liebert, C., Summers, A.O., White, D.G., Maurer, J.J., 2001. Incidence of class 1 and 2 integrases in clinical and commensal bacteria from livestock, companion animals, and exotics. Antimicrob. Agents Chemother. 45 (3), 723-726.

Hijnen, W.A.M., Beerendonk, E.F., Medema, G.J., 2006. Inactivation credit of 
UV ra- diation for viruses, bacteria and protozoan (oo)cysts in water: a review. Water Res. 40 (1), 3-22.

Li, L.S., Zhu, W.P., Zhang, P.Y., Zhang, Q.Y., 2007. Removal of organic matter in municipal wastewater by combined use of $\mathrm{TiO} 2$ photocatalytic ozonation and biologically activated carbon. Zhongguo Huanjing Kexue/China Environ. Sci. 27 (5), 627-632.

Lui, G.Y., Roser, D., Corkish, R., Ashbolt, N., Jagals, P., Stuetz, R., 2014. Photovoltaic powered ultraviolet and visible light-emitting diodes for sustainable point-of- use disinfection of drinking waters. Sci. Total Environ. 493, 185-196.

Mả rquez, G., Rodríguez, E.M., Beltr’an, F.J., Ả lvarez, P.M., 2014. Solar photocatalytic ozonation of a mixture of pharmaceutical compounds in water. Chemosphere 113, 71-78.

Marti, E., Balcả zar, J.L., 2013. Real-time PCR assays for quantification of qnr genes in environmental water samples and chicken feces. Appl. Environ. Microbiol. 79 (5), 1743-1745.

Mehrjouei, M., Müller, S., Mœller, D., 2015. A review on photocatalytic ozonation used for the treatment of water and wastewater. Chem. Eng. J. 263, 209-219.

Michael, I., Rizzo, L., McArdell, C.S., Manaia, C.M., Merlin, C., Schwartz, T., Dagot, C., Fatta-Kassinos, D., 2013. Urban wastewater treatment plants as hotspots for the release of antibiotics in the environment: a review. Water Res. 47 (3), 957-995.

Moreira, N.F.F., Orge, C.A., Ribeiro, A.R., Faria, J.L., Nunes, O.C., Pereira, M.F.R., Silva, A.M.T., 2015. Fast mineralization and detoxification of amoxicillin and diclofenac by photocatalytic ozonation and application to an urban wastewater. Water Res. 87, 87-96.

Narciso-da-Rocha, C., Varela, A.R., Schwartz, T., Nunes, O.C., Manaia, C.M., 2014. blaTEM and vanA as indicator genes of antibiotic resistance contamination in a hospitaleurban wastewater treatment plant system. J. Glob. Antimicrob. Resist. 2 (4), 309-315.

Nelson, K.Y., McMartin, D.W., Yost, C.K., Runtz, K.J., Ono, T., 2013. Point-of-use water disinfection using UV light-emitting diodes to reduce bacterial contamination. Environ. Sci. Pollut. Res. 20 (8), 5441-5448.

Omoruyi, I.M., Pohjanvirta, R., 2015. Estrogenic activity of wastewater, bottled waters and tap water in Finland as assessed by a yeast bio-reporter assay. Scand. J. Public Health 43 (7), 770-775.

Pei, R., Kim, S.C., Carlson, K.H., Pruden, A., 2006. Effect of river landscape on the sediment concentrations of antibiotics and corresponding antibiotic resistance genes (ARG). Water Res. 40 (12), 2427-2435.

Quici, N., Vera, M.L., Choi, H., Puma, G.L., Dionysiou, D.D., Litter, M.I., Destaillats, H., 2010. Effect of key parameters on the photocatalytic oxidation of toluene at low concentrations in air under $254185 \mathrm{~nm}$ UV irradiation. 
Appl. Catal. B 95 (3e4), 312-319.

Quiñ ones, D.H., Ả lvarez, P.M., Rey, A., Beltrả n, F.J., 2015. Removal of emerging contaminants from municipal WWTP secondary effluents by solar photo- catalytic ozonation. A pilot-scale study. Sep. Purif. Technol. 149, 132-139.

Restivo, J., Ơ rfã o, J.J.M., Pereira, M.F.R., Vanhaecke, E., Rønning, M., Iouranova, T., Kiwi-Minsker, L., Armenise, S., Garcia-Bordejẻ, E., 2012a. Catalytic ozonation of oxalic acid using carbon nanofibres on macrostructured supports. Water Sci. Technol. 65 (10), 1854-1862.

Restivo, J., O’ rfã o, J.J.M., Armenise, S., Garcia-Bordejẻ, E., Pereira, M.F.R., 2012b. Catalytic ozonation of metolachlor under continuous operation using nano- carbon materials grown on a ceramic monolith. J. Hazard. Mater. 239e240, 249-256.

Rey, A., García-Muñoz, P., Hernả ndez-Alonso, M.D., Mena, E., GarcíaRodríguez, S., Beltrản, F.J., 2014. WO3-TiO2 based catalysts for the simulated solar radiation assisted photocatalytic ozonation of emerging contaminants in a municipal wastewater treatment plant effluent. Appl. Catal. B 154e155, 274-284.

Ribeiro, A.R., Nunes, O.C., Pereira, M.F.R., Silva, A.M.T., 2015a. An overview on the advanced oxidation processes applied for the treatment of water pollutants defined in the recently launched directive 2013/39/EU. Environ. Int. 75, 33-51.

Ribeiro, A.R., Pedrosa, M., Moreira, N.F.F., Pereira, M.F.R., Silva, A.M.T., 2015b. Environmental friendly method for urban wastewater monitoring of micro- pollutants defined in the directive 2013/39/EU and decision 2015/495/EU. J. Chromatogr. A 1418, 140-149.

Rizzo, L., Della Sala, A., Fiorentino, A., Li Puma, G., 2014. Disinfection of urban wastewater by solar driven and UV lamp-TiO2 photocatalysis: effect on a multi drug resistant Escherichia coli strain. Water Res. 53, 145-152.

Sampaio, M.J., Silva, C.G., Silva, A.M., Vilar, V.J., Boaventura, R.A., Faria, J.L., 2013. Photocatalytic activity of TiO2-coated glass raschig rings on the degradation of phenolic derivatives under simulated solar light irradiation. Chem. Eng. J. 224 (1), 32-38.

S'anchez, L., Peral, J., Domé nech, X., 1998. Aniline degradation by combined photocatalysis and ozonation. Appl. Catal. B 19 (1), 59-65.

Tanaka, T., Tsuzuki, K., Takagi, T., 2001. Chemical oxidation of organic matter in secondary-treated municipal wastewater by using methods involving ozone, ultraviolet radiation and $\mathrm{TiO} 2$ catalyst. Water Sci. Technol. 43 (10), 295-302.

Thayanukul, P., Kurisu, F., Kasuga, I., Furumai, H., 2013. Evaluation of microbial regrowth potential by assimilable organic carbon in various reclaimed water and distribution systems. Water Res. 47 (1), 225-232.

Trintinaglia, L., Bianchi, E., Silva, L., Nascimento, C., Spilki, F., Ziulkoski, A., 2015. 
Cytotoxicity assays as tools to assess water quality in the Sinos River basin. Braz. J. Biol. 75, 75-80.

Vaz-Moreira, I., Nunes, O.C., Manaia, C.M., 2014. Bacterial diversity and antibiotic resistance in water habitats: searching the links with the human microbiome FEMS Microbiol. Rev. 38 (4), 761-778.

Volkmann, H., Schwartz, T., Bischoff, P., Kirchen, S., Obst, U., 2004. Detection of clinically relevant antibiotic-resistance genes in municipal wastewater using real-time PCR (TaqMan). J. Microbiol. Methods 56 (2), 277-286.

Xi, C., Zhang, Y., Marrs, C.F., Ye, W., Simon, C., Foxman, B., Nriagu, J., 2009. Prevalence of antibiotic resistance in drinking water treatment and distribution systems. Appl. Environ. Microbiol. 75 (17), 5714e5718.

Xiao, J., Xie, Y., Cao, H., 2015. Organic pollutants removal in wastewater by heterogeneous photocatalytic ozonation. Chemosphere 121,1-17.

Megura, B., Heath, E., Mernosa, A., Filipie, M., 2009. Combination of in vitro bioassays for the determination of cytotoxic and genotoxic potential of wastewater, sur- face water and drinking water samples. Chemosphere 75 (11), 1453-1460.

Zhao, X., Hu, H.-Y., Yu, T., Su, C., Jiang, H., Liu, S., 2014. Effect of different molecular weight organic components on the increase of microbial growth potential of secondary effluent by ozonation. J. Environ. Sci. 26 (11), 21902197. 


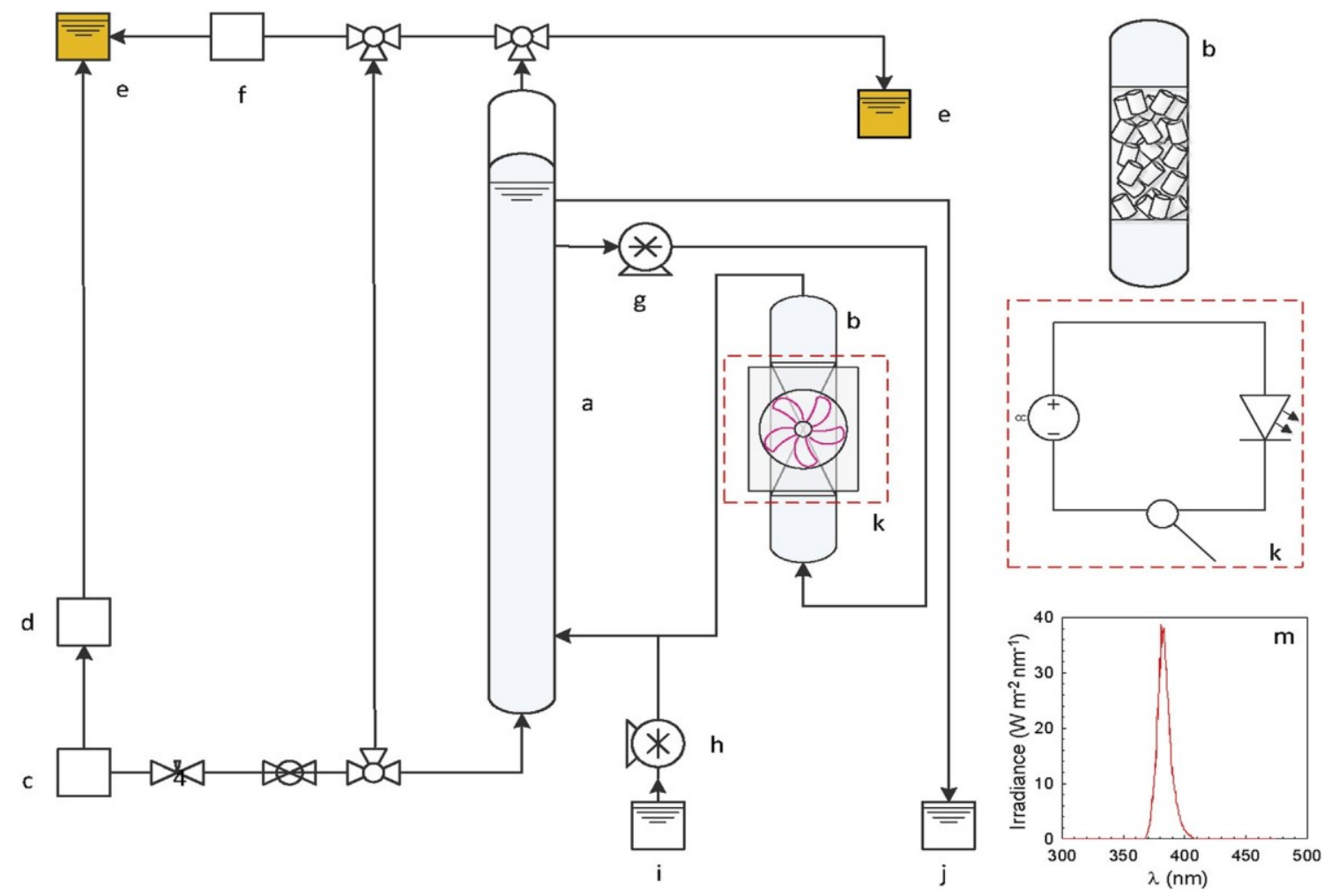

Fig. 1. Experimental set-up of the homemade photocatalytic reactor able to work in continuous mode: (a) Column for gaseliquid contact; (b) Column for liquidesolid contact (Raschig rings); (c) Ozone generator; (d) Mass flow controller; (e) Ozone gas destroyer; (f) Ozone gas monitor; (g) Peristaltic pump for recirculation; (h) Peristaltic pump; (i) Inlet solution; (j) Outlet solution; (k) LEDs; (m) LEDs irradiance spectrum

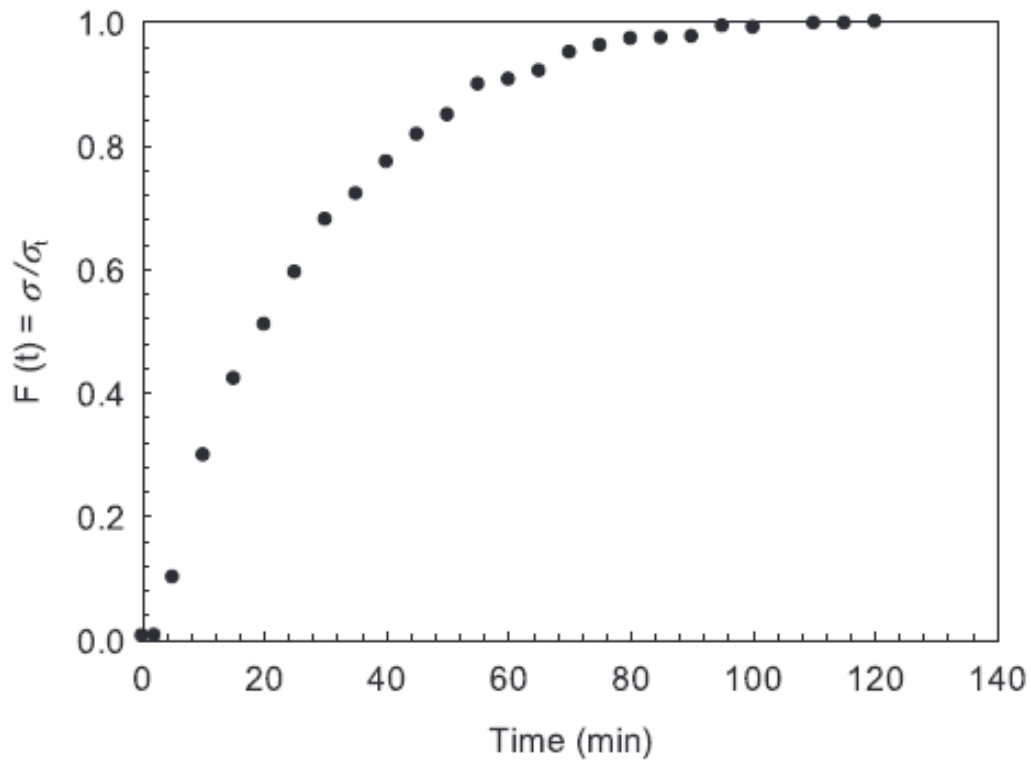

Fig. 2. Normalized conductivity (s/s t) of the outlet solution, introducing an inlet $\mathrm{NaCl}$ solution $\left(2000 \mathrm{mg} \mathrm{L}^{-1}\right)$. $\mathrm{s}$ is the conductivity of the outlet solution and $\mathrm{s} t$ the conductivity of the tracer injected in the column. 

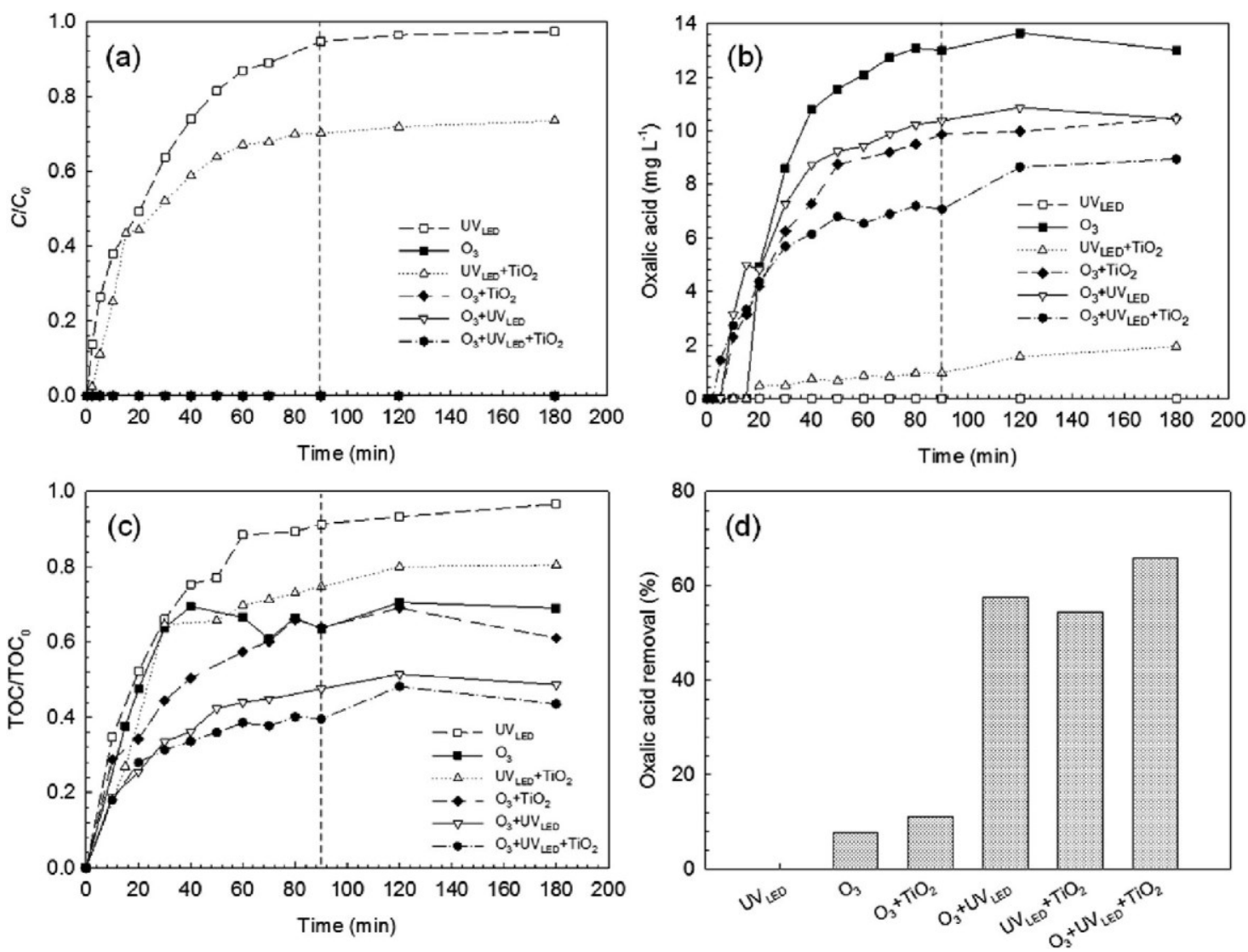

Fig. 3. (a) Normalized concentration $(\mathrm{C} / \mathrm{CO})$ of diclofenac in ultrapure water (C0 $=32 \mathrm{mg} \mathrm{L}-1)$, (b) evolution of its oxalic acid by-product concentration, and (c) respective normalized TOC content (TOC/TOC0) under different advanced processes. (d) Removal of oxalic acid when used as feed (C0 $=90 \mathrm{mg} \mathrm{L}-1)$. Experiments started with the column filled with ultrapure water only (without pollutant at $t=0 \mathrm{~min}$ ), the steady state was obtained at ca. $90 \mathrm{~min}$ and the retention time is $26 \mathrm{~min}$. 


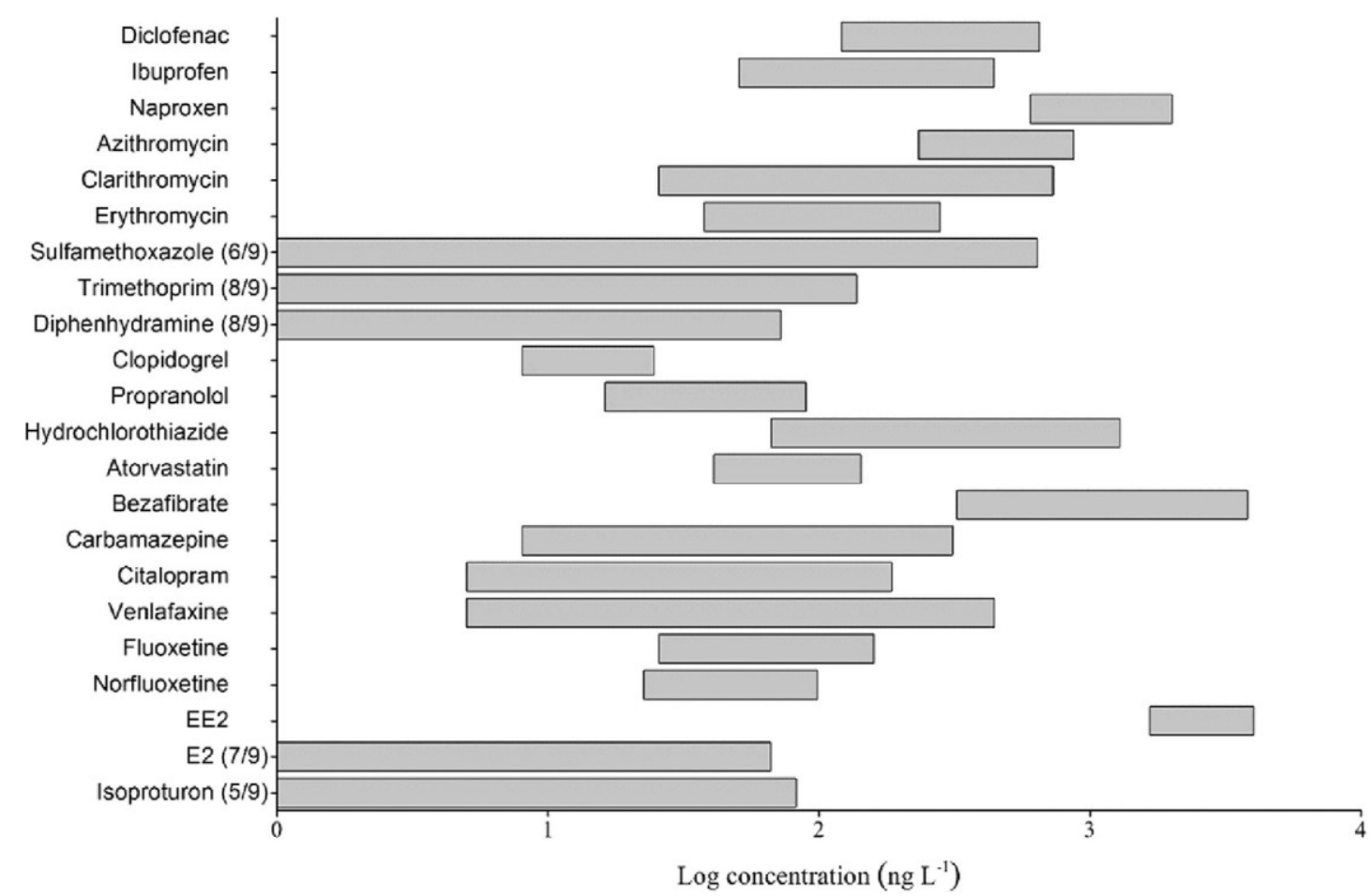

Fig. 4. Logarithmic range of concentrations (ng $\left.\mathrm{L}^{-1}\right)$ of the detected micropollutants in WWTP samples collected after the secondary biological treatment. The frequency of occurrence was 100\% (9/9) for all compounds, except when indicated. 


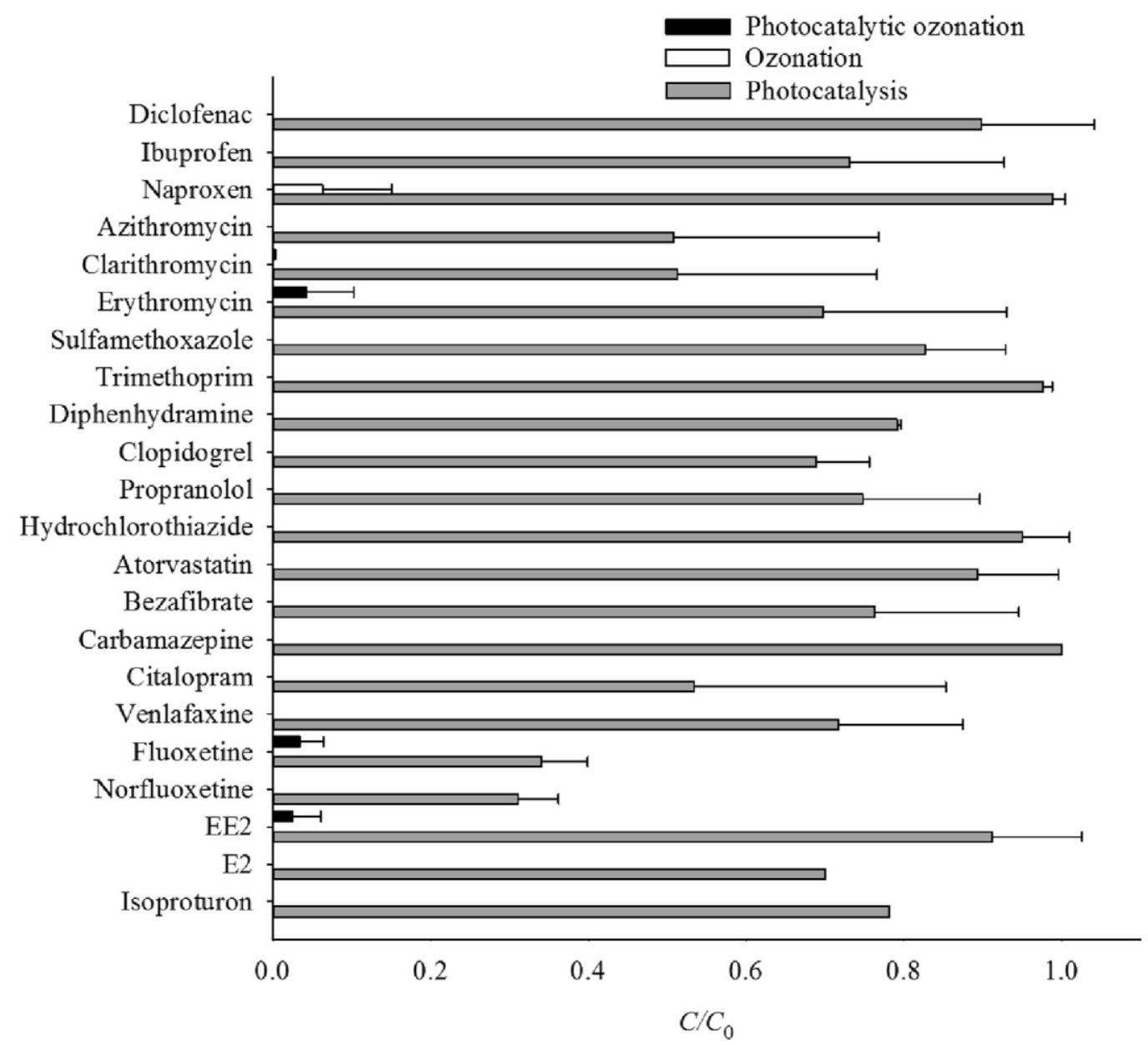

Fig. 5. Normalized concentration of micropollutants $(\mathrm{C} / \mathrm{C} 0)$ in the effluents from urban WWTP treated by photocatalysis, ozonation and photocatalytic ozonation; $\mathrm{C} 0$ refers to the concentration before treatment and $\mathrm{C}$ to that after treatment (retention time: $26 \mathrm{~min}$ ); compounds with C0 below the LOD before treatment are not shown. 

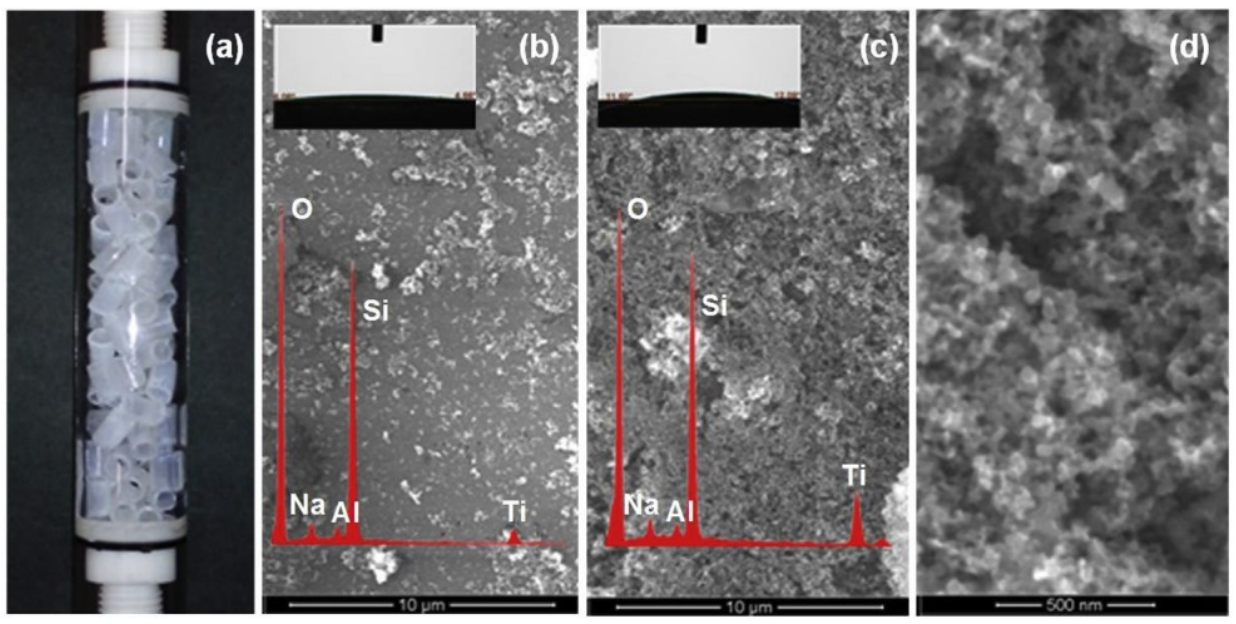

Fig. 6. (a) TiO2-coated glass Raschig rings and respective (b, c, d) SEM micrographs, EDS and contact angles (b) before and (c, d) after photocatalytic ozonation.

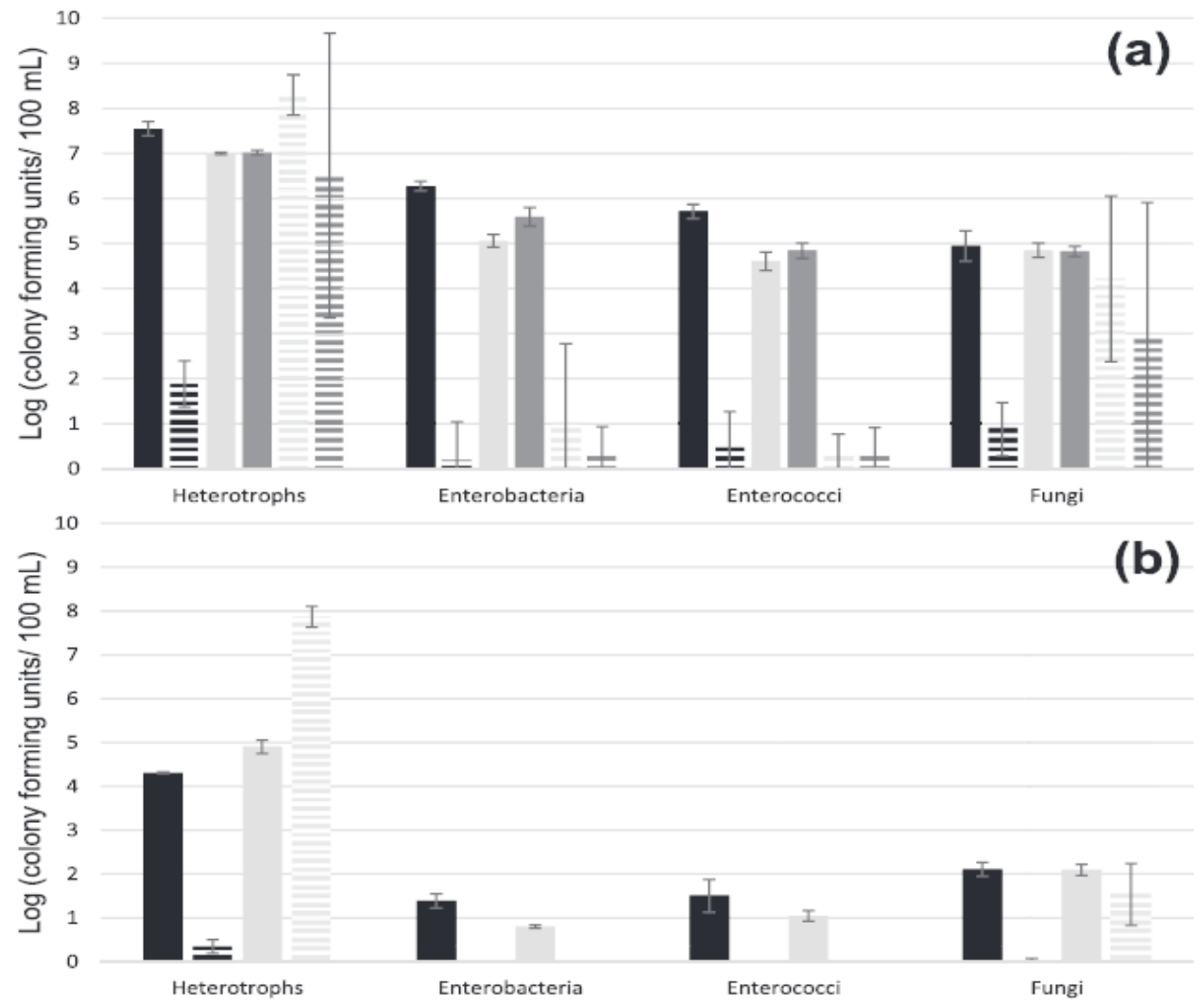



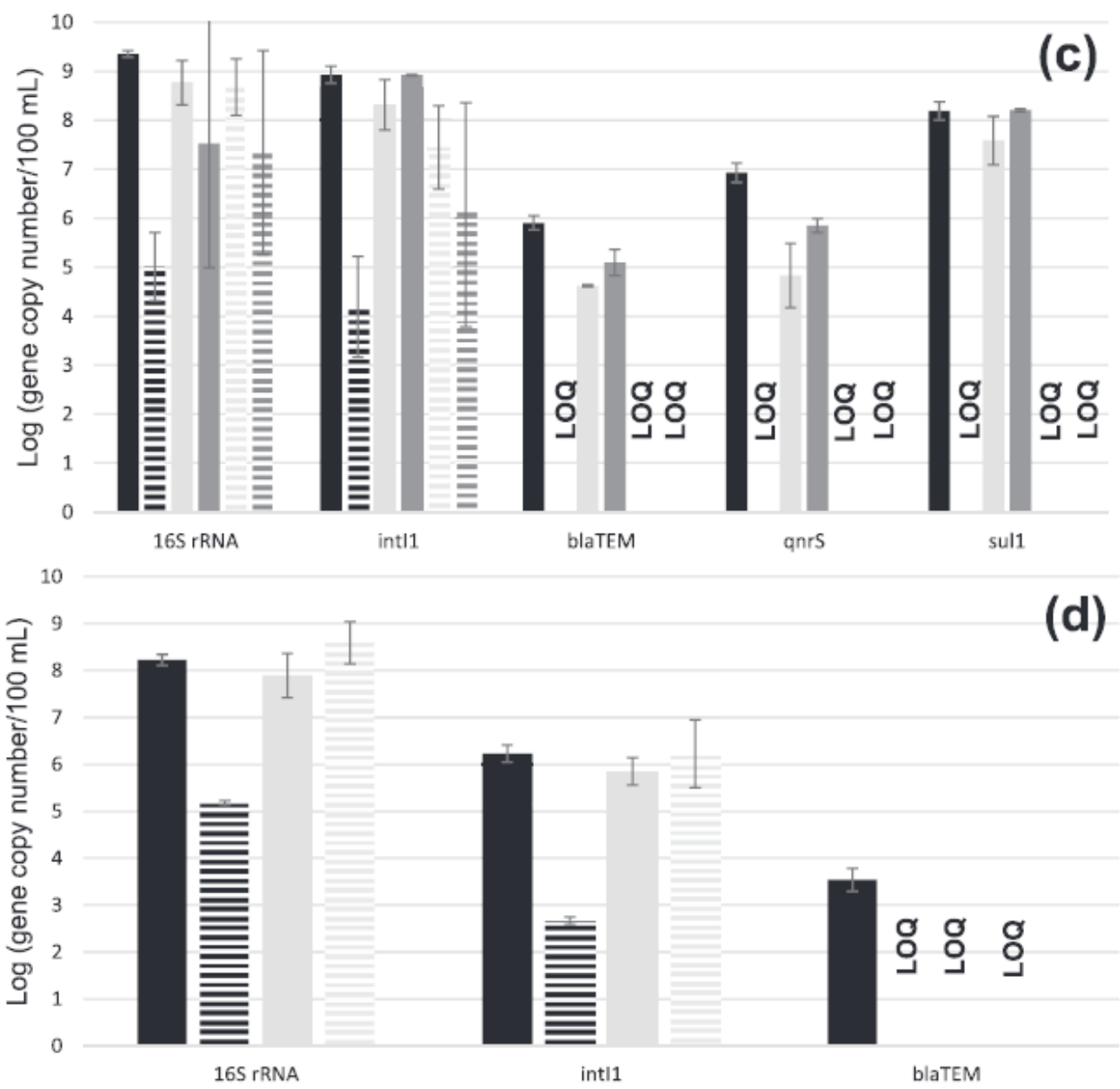

Fig. 7. Microbial inactivation by photocatalytic ozonation in continuous reaction performed on wastewater effluents (a, c) and surface water (b, d) was assessed based on the quantification of selected microbial groups using culture-dependent methods (a, b) and qPCR of selected genes (c, d), in non-treated control samples (filled bars) and after a treatment retention time of 26 min (striped bars), at the initial time (black) and after 3-days storage at room temperature with light (grey) or in the dark (dark grey). LOQ, below or close to the limit of quantification (at least more than half of the quantification reactions were below the quantification limit and none was more than 3 times above that value). 


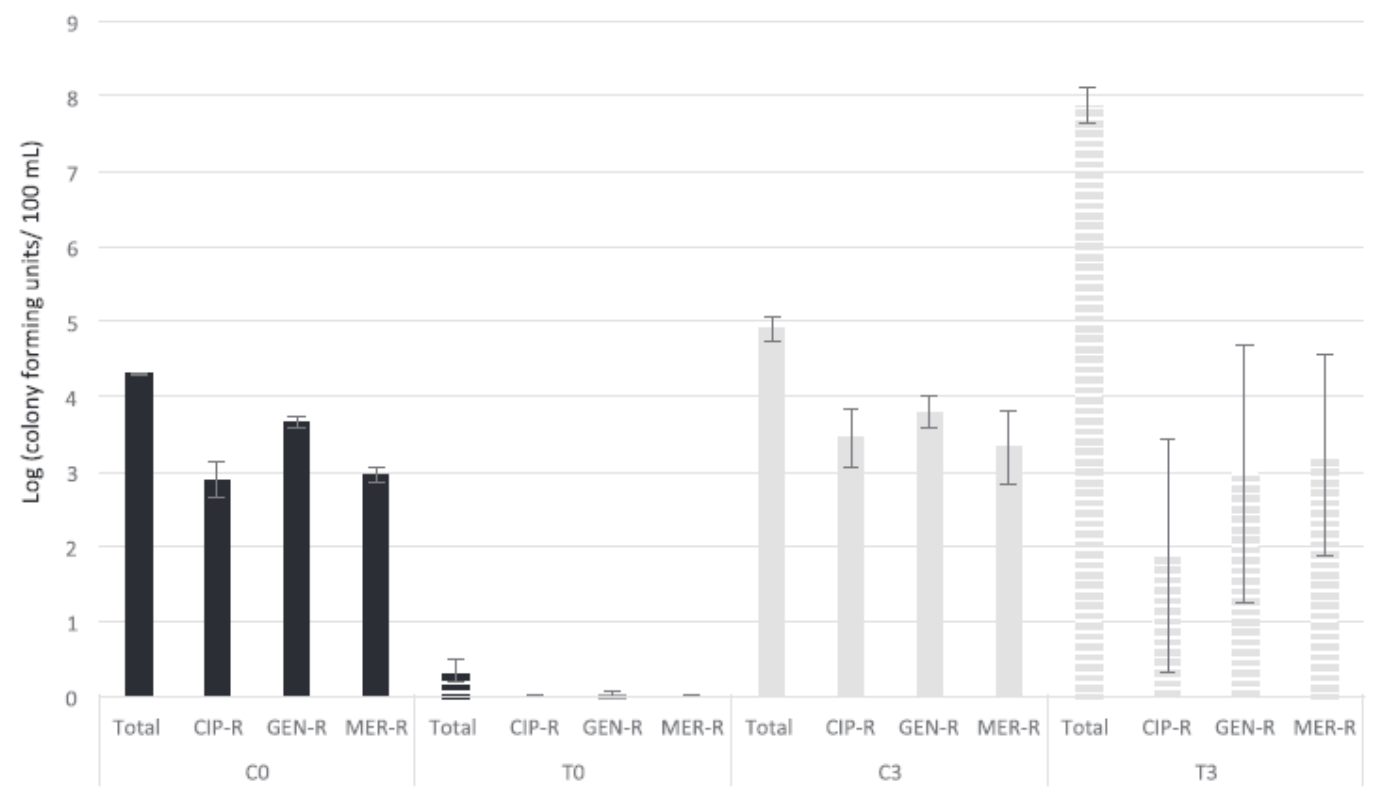

Fig. 8. Total, ciprofloxacin resistant (CIP-R), gentamicin resistant (GEN-R) and meropenem resistant (MER-R) heterotrophic counts before (C0), after photocatalytic ozonation treatment (T0) and after 3-days incubation of untreated surface water (C3) and treated surface water (T3) at dark conditions for microbial reactivation assessment. 
Table 1

Conditions used in quantitative PCR assays

\begin{tabular}{|c|c|c|c|c|c|}
\hline Gene & Primers & Reference & $\begin{array}{l}\text { Efficiency } \\
(\%)\end{array}$ & Conditions & Reference \\
\hline $16 \mathrm{~S}$ rRNA & $\begin{array}{l}1114 \mathrm{~F} \\
\text { (CGGCAACGAGCGCAACCC) } \\
\text { 1275R (CCATTGTAGCACGTGTGTAGCC) }\end{array}$ & $\begin{array}{l}\text { Escherichia coli } \\
\text { ATCC } 25922\end{array}$ & 100 & $\begin{array}{l}95^{\circ} \mathrm{C} \text { for } 10 \mathrm{~min}(1 \mathrm{cycle}) \\
95^{\circ} \mathrm{C} \text { for } 15 \mathrm{~s}, 55^{\circ} \mathrm{C} \text { for } 20 \mathrm{~s} \text { and } \\
72^{\circ} \mathrm{C} \text { for } 10 \mathrm{~s} \text { ( } 35 \text { cycles) } \\
\text { Other: } 1 \mathrm{a}\end{array}$ & $\begin{array}{l}\text { (Denman and MCSweeney, } \\
\text { 2006) }\end{array}$ \\
\hline blaTEM & $\begin{array}{l}\text { blaTEM-F (TTCCTGTTTTTGCTCACCCAG) } \\
\text { blaTEM-R (CTCAAGGATCTTACCGCTGTTG) }\end{array}$ & Escherichia coli (A2FCC14) & 96 & $\begin{array}{l}95^{\circ} \mathrm{C} \text { for } 10 \mathrm{~min} \text { ( } 1 \text { cycle) } \\
95^{\circ} \mathrm{C} \text { for } 15 \mathrm{~s}, 60^{\circ} \mathrm{C} \text { for } 30 \mathrm{~s} \text { and } \\
72^{\circ} \mathrm{C} \text { for } 10 \mathrm{~s} \text { ( } 40 \text { cycles) } \\
\text { Other: } 2 \mathrm{a}\end{array}$ & (Bibbal et al., 2007) \\
\hline intl1 & $\begin{array}{l}\text { intl1-F } \\
\text { (CCTCCCGCACGATGATC) } \\
\text { intl1-R } \\
\text { (TCCACGCATCGTCAGGC) }\end{array}$ & Escherichia coli (A2FCC14) & 94 & $\begin{array}{l}95^{\circ} \mathrm{C} \text { for } 10 \mathrm{~min}(1 \mathrm{cycle}) \\
95^{\circ} \mathrm{C} \text { for } 15 \mathrm{~s}, 55^{\circ} \mathrm{C} \text { for } 30 \mathrm{~s} \text { and } \\
72^{\circ} \mathrm{C} \text { for } 10 \mathrm{~s} \text { ( } 40 \text { cycles) } \\
\text { Other: } 1 \mathrm{a}\end{array}$ & (Goldstein et al., 2001) \\
\hline qners & $\begin{array}{l}\text { qnrSrtF11 (GACGTGCTAACTTGCGTGAT) } \\
\text { qnrSrtR11 (TGGCATTGTTGGAAACTTG) }\end{array}$ & Enterobacter cloacae (S1+) & 95 & $\begin{array}{l}95^{\circ} \mathrm{C} \text { for } 5 \mathrm{~min}(1 \mathrm{cycle}) \\
95^{\circ} \mathrm{C} \text { for } 15 \mathrm{~s}, 60^{\circ} \mathrm{C} \text { for } 1 \mathrm{~min} \text { ( } 40 \text { cycles) } \\
\text { Other: } 2 \mathrm{c}\end{array}$ & (Marti and Balcázar, 2013) \\
\hline sul1 & $\begin{array}{l}\text { sul1-FW (CGCACCGGAAACATCGCTGCAC) } \\
\text { sul1-RV (TGAAGTTCCGCCGCAAGGCTCG) }\end{array}$ & Achromobacter sp. & 94 & $\begin{array}{l}95^{\circ} \mathrm{C} \text { for } 5 \mathrm{~min}(1 \mathrm{cycle}) \\
95^{\circ} \mathrm{C} \text { for } 15 \mathrm{~s}, 60^{\circ} \mathrm{C} \text { for } 1 \mathrm{~min}(40 \text { cycles }) \\
\text { Other: } 2 \mathrm{~b}\end{array}$ & (Pei et al., 2006) \\
\hline $\operatorname{van} A$ & $\begin{array}{l}\text { vanA3FP } \\
\text { (CTGTGAGGTCGGTTGTGCG) } \\
\text { vanA3RP } \\
\text { (TTTGGTCCACCTCGCCA) }\end{array}$ & $\begin{array}{l}\text { Enterococcus faecalis } \\
\text { (H1EV23) }\end{array}$ & 98 & $\begin{array}{l}95^{\circ} \mathrm{C} \text { for } 5 \mathrm{~min}(1 \mathrm{cycle}) \\
95^{\circ} \mathrm{C} \text { for } 15 \mathrm{~s}, 60^{\circ} \mathrm{C} \text { for } 1 \mathrm{~min} \text { ( } 40 \text { cycles) } \\
\text { Other: } 2 \mathrm{a}\end{array}$ & (Volkmann et al., 2004) \\
\hline
\end{tabular}

1) KAPA SYBR ${ }^{\curvearrowleft}$ FAST ABI Prism ${ }^{\curvearrowleft}$ qPCR Master Mix; 2) SYBR $^{\curvearrowleft}$ Select Master Mix; a) $200 \mathrm{nM}$ of primer; b) $400 \mathrm{nM}$ of primer; c) $600 \mathrm{nM}$ of primer. 
Table 2

Concentration of the micropollutants detected in surface water collected during three sampling campaigns, between May and June 2015, and normalized concentration after treatment (C/C0).

\begin{tabular}{lllllll}
\hline & $C_{0}\left(\mathrm{ng} \mathrm{L}^{-1}\right)$ & $C / C_{0}$ & $C_{0}\left(\mathrm{ng} \mathrm{L}^{-1}\right)$ & $C / C_{0}$ & $C_{0}\left(\mathrm{ng} \mathrm{L}^{-1}\right)$ & $C / C_{0}$ \\
\hline Clarithromycin & 4.13 & 0 & 1.36 & 0 & 2.11 & 0 \\
Fluoxetine & 5.72 & 0 & $<\mathrm{LOQ}$ & 0 & $<\mathrm{LOQ}$ & 0 \\
Norfluoxetine & 7.66 & 0 & $<\mathrm{LOD}$ & n.a. & $<\mathrm{LOD}$ & n.a. \\
Carbamazepine & $<\mathrm{LOQ}$ & 0 & 35.1 & 0 & 56.2 & 0 \\
E2 & $<\mathrm{LOQ}$ & 0 & $<\mathrm{LOQ}$ & 0 & $<\mathrm{LOQ}$ & 0 \\
EE2 & $<\mathrm{LOD}$ & n.a. & $<\mathrm{LOQ}$ & 0 & $<\mathrm{LOQ}$ & 0 \\
Isoproturon & $<\mathrm{LOQ}$ & 0 & 24.3 & 0 & 21.3 & 0 \\
\hline
\end{tabular}

LOD: limit of detection; LOQ: limit of quantification; n.a.: not applicable.

Table 3

Results (percentage) from MTTa and $\mathrm{LDH}^{\mathrm{b}}$ assays before and after treatment of urban wastewater sample

\begin{tabular}{|c|c|c|c|c|}
\hline \multirow[t]{2}{*}{ Cell line } & \multicolumn{2}{|l|}{ MTT assay } & \multicolumn{2}{|l|}{ LDH assay $^{c}$} \\
\hline & Before treatment & After treatment & Before treatment & After treatment \\
\hline Caco-2 & $92 \pm 20$ & $59 \pm 11$ & $55.3 \pm 3.1(51.5 \pm 4.6)$ & $49.0 \pm 3.3(49.5 \pm 4.0)$ \\
\hline hCMEC/D3 & $106 \pm 10$ & $58 \pm 21$ & $61.1 \pm 3.7(66.6 \pm 7.0)$ & $60.3 \pm 4.2(67.4 \pm 5.5)$ \\
\hline L.929 & $120 \pm 19$ & $91 \pm 10$ & $50.7 \pm 2.5(51.6 \pm 3.0)$ & $55.7 \pm 3.2(56.7 \pm 3.3)$ \\
\hline
\end{tabular}

${ }^{a}$ Values for culture media were $100 \%$ (RSD $<20 \%$ ) and between 1.3 and $10 \%$ for Triton X-100 (total disruption of cells).

b Values for Triton X-100 (total disruption of cells) were $100 \%$ (RSD $<8 \%$ ).

${ }^{c}$ Values in parentheses correspond to blank values obtained in culture media only (intact cells) 